\title{
Modern Industrial Products Color Research and Art Design
}

\author{
Liaoliao $\mathrm{Ji}^{1,}$ a Yilei Liu ${ }^{1, \text { a }}$ \\ ${ }^{1}$ Pingxiang University, Pingxiang, Jiangxi, China, 337055 \\ ${ }^{\mathrm{a} e m a i l,}{ }^{\mathrm{b}}$ email,
}

\section{Keywords: Modern Industrial Products, Color Research, Art Design}

\begin{abstract}
Industrial product design is kind of creative activity of mankind through practice arising and the purpose is to change their living conditions and living conditions, strengthen practical function and aesthetic value of the product, complete the product design under the guidance of aesthetic principles is very important, use of color as an industrial product design important content, the focus has always been designed as a product exists, the best color scheme design of the product has a crucial role in the design of industrial products, at present, as people aesthetic level improve, more and more enterprises begin to focus on the use of color research in the industrial product design process, how the modern industrial products color art design has become the focus of product development and design.
\end{abstract}

\section{Introduction}

Industrial products that people live and work tools, product design starting point and destination are "people." Color design of industrial products, it is important to have the entire industrial product design process for a modern ring designs. Color is the first element of the visual design of the product, good product color design is not only to attract the attention of consumers, but also in product design art show at the same time, the designer of emotion through color more effectively communicated to consumers, enhance consumer product by product and the brand impression. 'American popular color survey research center, has suggested that there is a law of 'seven seconds' time in the selection of goods: the face of an array of goods, people just seven seconds to determine whether these goods invigoration rejection. During this brief but crucial 7 seconds, the role of color accounted for $67 \%$ of the people decided to become a major factor in commodity likes and dislikes. How to design the product the best color scheme is the focus when the current enterprise product development and design serious attention. From a business perspective, is designed to investigate the source of competitive advantage, full color study is a modern enterprise expanded color marketing, to enhance the value of the product guarantee.

With the design of industrial products in China's rapid development, more and more companies recognize the status and role of industrial product design and product development in a wider area in the study of all aspects of industrial product design also emerged. This article only discussed the case of industrial products based on color research.

\section{The Importance of Color Using in the Industrial Product Design}

The use of color for the role of industrial design is very important, product design and use of color are closely related and indivisible part two, we can say that is the external characteristics of color products, can achieve good color to use during the industrial product design directly related to the people's desire for consumption, the color appearance of the product can not only play a decorative role, but also can create cost-competitive with high added value, and therefore, we say that the use of color for industrial product design has an irreplaceable role, specific to that is reflected in the following aspects.

Appearance for the product itself cannot be ignored, which means that color plays a decisive role in product design. Therefore, the modern industrial product design process should not only focus on product quality, but also pay attention to the appearance of the product, to further improve the aesthetic value of the product. Successful industrial products need to match the color scheme for the 
two complement each other, which is the product of the first visual design elements. It is well known for other elements of the color impression are particularly strong, the impact of strong colors will make people have a strong visual impact, deepen people's impression of the product.

Currently, industrial products have become ubiquitous in our lives, product design requires constant innovation in order to improve their competitiveness, and color information consumer behavior will have a huge impact, therefore, a suitable color matching can inspire consumption those who desire to buy has become an important way to enhance the competitiveness of their products, which means that the strengthening of industrial product design, color scheme and design for enhancing the competitiveness of products has an indispensable role. Successful sales of color design of the product will play a catalytic role to attract consumers to buy.

Today, a wide range of industrial product design, industrial products aura gradually receded into very well known very common public goods, in this case, we should start thinking about other positive factors to show the commercial value of the product, and color design is to improve product value, product to show the best elements of commercial value. Color has become one of the major factors affecting sales, according to statistics, only need to add a small amount of investment in terms of color design, can help improve the product by $15 \%-30 \%$ of the value-added, the color scheme is often used as the main basis of the value of goods First, the considerations cannot be ignored during the industrial product design, therefore, industrial product design, use of color to give full play to the advantages of low cost and high return.

\section{The Lack of Color Application of Existing Product Design}

"There is no color in the design is the lack of vitality." As the most intense visual impact, color plays the role of a head start in people's lives, always reveals the designer's personal charm. Throughout the changing world of color, color improper application of the phenomenon mainly for the following two points:

People often describe the colorful exposure to commodity-rich situation today, however, the face of the market homogeneous similar domestic and foreign products, people are more likely to be attracted to foreign products, the reason is that foreign products beautiful, harmonious colors application. Many designs on the market today, is rapidly getting rid of past monotonous color, and become dazzling, colorful, often with a strong tone of high purity and color contrast color combinations to represent the semantics of these uncoordinated handling would seriously affect the beauty products.

The rapid development of the information age, people's ideas diversified development, individual pursuit and color in imitation, in a free, casual, even accidental spontaneous manner. Human life in the changing natural environment, throughout the year, day and night, morning twilight alternating changes in nature constitute season, climate, temperature, color, plant growth and other factors, will result in changing the color of the objective environment, which by the nature of determined by objective laws, not man's will to change, a different environment will cause people of color in the color at different times demanding.

\section{The Product Color Design Methods}

Product color art design includes artistic design and rational design. Product color artistic design refers contrast to reconcile, balance and stability, proportional division and rhythm and other art handling will use different colors to produce Lu among the outstanding artistic beauty product, shaping brand image and product Lu. Color of product design rationality is defined according to the material, functionality, use a ring pull, integrated elements of the man-machine characteristics, processing, production cost and specific design requirements to properly select the color. Product color design, color choice should be up in the rationality of the design basis of the color accentuated artistic process - the artistic design in which the color and style of shaping the product color is to grasp the main aspects of playing color artistic design.

The product should be based on product color features, both `salient aspects of" integration 'two 
aspects, both highlight and enhance co-smooth touch aspect closed. highlight products color scheme design should grasp: strengthening lightness in contrast, the focus of outstanding products, such as mobile phone keypad and display; body color suppression product using the 'highlights the importance of a design to steal the details of the products, improve the operability of the product, such as lathe control switches; the use of contrasting colors (complementary color) to enhance contrast, quasi contrasting colors (departing complementary color) is contrasted with the smooth coexistence;.. the use of a super measures with the ability achromatic black and universal harmonic color 'white' black regardless of any bath with color can play a role in promotion, which is also the reason why black handset more popular reason, and white can make contrast detente while highlighting the overall effect. In addition, the metallic silver may be well with a variety of measures with colors, with silver as the main color of electronic products was widely recognized by consumers. The type 'color scheme products designed to enhance the contrast of the 3 properties, and "fusion' color scheme should be designed to weaken color contrast effect. 'Converged 'products matching method as follows: Use the same color, so that the products of unity and concord, to grasp the color difference between the change in design, such as chromatic aberration small color results in a stable, warm, gentle product artistic effect $\mathrm{Li}$ with lightness unified to create products. sense of stability; the use of colors to create the style of products, such as cashmere drawn from the same hue similar "two-tone" combination of two colors, manufacture color difference, down into the cloud is a combination of color, can create a rich color table idler .

Product color design if not consistent with the form of the products, then there is no beautiful color value, the color image of the shape is an important element in shaping the style of the product. Usually determines the color of the product of three elements of hue, hue, and contrast. One of the most important is the tone, even for the same product, when the color tone is changed, the product will exhibit different styles. Compared to the same hue, hue, contrast, color products to strengthen product design can add vigor and contrary to reduce the contrast between the products will create calm style. In addition, "Contrast can into the product color, style art handling, by brightness contrast, the integrated use of Purity, color contrast, hue contrast and an area of contrast and other techniques, to achieve product color harmony design. Color of product to be considered when designing the dynamic changes color under the working condition of the product, such as color display's color, the working interface, as well as color changes, etc. should work under the product with the main color coordinated with measures, in order to further shape the artistic product style.

\section{The Issues That Need Attention of Color Using in Industrial Product Design}

Color in industrial product design in the use is very important but it is not blind to color use in the industrial product design process, but also pay attention to some problems, specifically, the following points:

Different people career choice of color usually there is a big difference, such as kindergartens, a snack bar in the choice of industrial products tend to choose some bright colors bright colors, while hospitals, museums in the choice of the color of industrial products tend to choose some solemn color, and secondly, regional differences also lead to a different color choices, different countries and regions of the color of people have different hobbies, so during the product design to consider user likes and dislikes, for example, in some of the northern region prefer warm and lively color preference in the southern region of some sober pastel colors. in addition, during the industrial use of color production design must take into account the consumer's age, meet the age characteristics of consumers, but to meet the psychological and consumer acceptance aesthetic taste, to meet the aesthetic requirements of different groups.

An industrial product has multiple components, should be the focus of attention during parts of the color of color, under the premise of the main colors determined for a color key configuration, and then the entire product finishing touch to play the role of industrial products the focus of the color typically used for important switch trademarks, factory, moving parts, etc. Therefore, in product design should focus on these important switch configuration choices are more intense colors to match the rest of the site to distinguish, you can use opposite the main tone harmonic color 
ratio, consider the product's overall visual effect. Also, note that in the design of industrial products, the brightness contrast determines the visibility of the level, the greater the difference in brightness, the higher the degree of visibility, on the contrary, brightness difference, the lower the degree of visibility, and therefore color the design will directly affect the safety and efficiency of operations, industrial product design use of color to give full consideration to the above two points, ensure good artistic effect and safety of operation.

In recent years, China's industrial development is very rapid, has made a lot of achievements, but in the world of industrial design in our country is still in a relatively backward position. Fusion product design should own national characteristics, to create their own product characteristics, and characteristics of the product depends on national history and culture of precipitation and habits. In China, the widespread industrial product design "Copy Production" phenomenon, product design and use of color are often caught mere imitation state, the characteristics of each country's industrial products are closely related to their culture, even though China started relatively modern industrial design late, but the huge potential for development, in product design should make full use of color when using the profound Chinese culture, and Chinese elements into the Chinese symbols in the design, must not be applied mechanically design experience of others, to focus on innovative use of color, comprehensive Chinese nation art element, in developed countries for reference product design ideas and concepts at the same time to build with Chinese characteristics, industrial products, to inject deep meaning.

\section{Conclusion}

The effect of color is one of the industrial product design quality metrics requires a combination of people's psychological and aesthetic tastes, from reality, give full play to the characteristics of color, add charm for industrial products, to achieve a harmonious color effect, give beauty, and how perfect the color used in the design of industrial products also need innovative designers, combined with the characteristics of the times, the color development of weapons design, the perfect combination of practicality and aesthetic products.

\section{Acknowledgements}

Fund Project: Jiangxi Arts and Sciences Planning Project (YG2015189, YG2014255), 2015 Annual Pingxiang City Science and Technology Support Program (Research and Development on the Central Region Animation Rendering Service Platform Based on the Cloud Computing).

\section{References}

[1] Li Ya. The color research in industrial design[J]. Mudanjiang University, 2013, 11

[2] Pan Jie. On the product color design characteristics and problems[J]. Art Education, 2011, 03

[3] Chen Yan. Analysis of colors in product design [J]. Journal Of Light Industry Textile \& Design, 2009, 03

[4] Wang Xin, Wang Xin. The color composition[M]. Wuhan: Hubei Fine Arts Publishing House, 2005.

[5] Qu Min, Zhang Feng. On the colors in product design psychological construct [J] Packaging Engineering, 2005, 26 (4): 198-200. 